International Journal of Biological Research, $2(2)(2014) 125-128$
International Journal of Biological Research
Journal home page: $\begin{gathered}\text { www.sciencepubco.com/index.php/IJBR } \\ \text { doi: } 10.14419 / \text { ijbr.v2i2.3415 } \\ \text { Research Paper }\end{gathered}$

\title{
Morphological descriptive study of giardia lamblia in man and cow at basrah
}

\author{
Rasha Khalil Al Saad $^{1 *}$, Ghazi Yaqoob Al Emarah ${ }^{2}$ \\ ${ }^{1}$ Lecturer, MSc Parasitology, Microbiology Department, Veterinary Medicine Collage, Basrah University, Basrah, Iraq \\ ${ }^{2}$ Dean, Assistant Professor, PhD Parasitology, Veterinary Medicine Collage, Basrah University, Basrah, Iraq \\ *Corresponding authorE-mail: masterr78@ymail.com
}

\begin{abstract}
Giardia was single celled microscopic protozoan parasites that cause enteric disease in human. Because of the impact on socio-economic development, especially in developing countries, it was included in the "Neglected Disease Initiative" of the World Health Organization. This work conducted to descript morphology of Giardia spp in different hosts, which is first study of its type in Basrah, Iraq. This work started from September 2012 till June 2013, through this period collected 2393 stool samples from human and cows. 727 out of 2393 were positive. By using golden standard microscopic methods for diagnosis. A selective 30 positive stool samples for each hosts, measured the dimensions of stages of Giardia. There is different measurement in dimensions of both two phases of Giardia.
\end{abstract}

Keywords: Giardia Lamblia, Trophozoite, Cyst, Lugol's Iodine, Giemsa.

\section{Introduction}

Giardia was a binucleate flagellated protozoan parasite that infected the upper intestinal tract of human and many animal species [1], [2]. Two distinct and specialized forms of Giardia exist, the cyst and trophozoite [3]. The oval cysts develop in the large intestine where they form a tough hyaline cyst wall [3]. These quadrinucleate cysts are robust and can survive for extended periods of time in a favorable environment [4]. Trophozoites are binucleate; possess four pairs of flagella, and an adhesive disc which is located on the ventral surface of the cell [5]. A pair of large, curved, transverse, dark-staining median bodies lies behind the adhesive disc [6]. These bodies are unique to Giardia [6], [7]. There are no mitochondria, Golgi bodies, or lysosomes and there is no smooth endoplasmic reticulum [8]. The overall effect of the two nuclei behind the lobes of the adhesive disc and the median bodies is that of a wry little face that seems to be peering back at the observer [7]. G. Duodenalis trophozoites contain two nuclei (binucleate) located in the anterior of the organism and the shape resembles that of a pear cut in half along its long axis (piriform). Trophozoites possess four pairs of flagella arranged in bilateral symmetry [7]. G. Duodenalis trophozoites possess anterio-lateral, ventro-lateral, posterio-lateral and caudal pairs of flagella with the caudal pair being ventral. Motile trophozoites exhibit forward movement during which they tend to rotate around their longitudinal axes displaying both a tumbling movement resembling that of a falling leaf and an up and down movement referred to as "skipping" [9]. Two "claw-hammer" shaped median bodies, composed of microtubules, lie transversely in the mid-portion of the organism [10]. Exposure to bile salts and alkaline $\mathrm{pH}$ as trophozoites pass down the small intestine induces them to encyst, rounding up and forming the immature binucleate cyst [11]. The cyst contains fewer identifiable organelles than the trophozoite. Apart from the nuclei, flagellar axonemes can often be seen running diagonally along the long axis of the cyst as can the crescentic fragments of the ventral disc. Whilst encysted, the nuclei of the single trophozoite undergo division to produce a mature cyst containing four nuclei located at one pole [10].

\section{Materials and methods}

\subsection{Regions of study}

The regions of work includes four locations in Basrah province, these are Al-Dier, Al-Qurnah, Al-Medina and Al-Thaghir.

\subsection{Man}

About 1344 stool samples were collected from human cases for different age, sex, address, economic state and service level, during period from10 September 2012 to 30 May 2013. All samples were taken from patients complain of diarrhea, abdominal discomfort, nausea and abdominal cramp whose attended to Al-Qurnah General Hospital, Centers of Al-Qurnah sector for Primary Health Care , Al-Medina General Hospital and Centers of Al-Medina sector for Primary Health Care and all samples collected in sterilized cups and taken up to laboratory of above centers, then the results transported to laboratory of Parasitology / College of Veterinary Medicine - University of Basrah for confirmed diagnosis.

\subsection{Cow}

In this study about 1049 cows' fecal samples were collected from different age, sex and health status, from areas of urban and rural locations of Al-Qurnah and Al-Medina, during period from September 2012 to May 2013. All fecal samples were collected freshly, directly from rectum or as soon as after defecation, collected samples stored in sterilized cups were used for each animal and all these cups were labeled by information with number, date of collection, animal condition, nature of feces, age of animal, ad- 
dress and name of owner. After collecting samples, transported to laboratory of Parasitology / College of Veterinary Medicine University of Basrah for confirmed diagnosis.

\subsection{Direct smear with Lugol's iodine}

After prepare the direct smear, used Lugol's iodine to kill and staining the trophozoites and cysts. Technique of this method: Adding of one drop of Lugol's iodine to prepared slide and examination by light microscope under, low (10X) and high power (40X) [10], [12], figure (1).

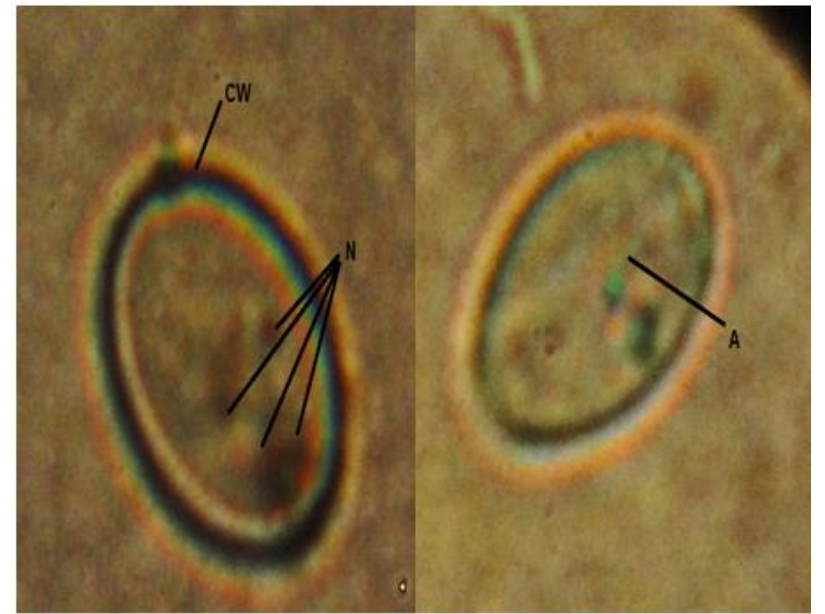

Fig. 1: Photomicrograph Of Giardia Cyst: Direct Smear with Lugol's Iodine, A and B (CW: Cyst Wall, N: Nucli, A: Axostyle), (400X).

\subsection{Direct smear with normal saline}

According to [12] and [13] direct smear as comminute 5-6 stool or faecal balls or 2-4 gm with pestle and mortar. Transfer a loop-fall of the material to a slide matchstick, and a drop of diluted fluid (normal saline) were placed on glass microscopic slide to form a uniform suspension. Spread it on the slide and apply cover slip. Examine the slide microscopically under low power (10X) and high power (40X), figures (2), (3) and (4). The positive stool samples divided into three groups according to parasite density [14]:

1) Heavy infection: 6-8 cysts or trophozoites per microscopic field.

2) Moderate infection: 3-5 cysts or trophozoites per microscopic field.

3) Mild infection: 1-2 cysts or trophozoites per microscopic field.

\subsection{Giemsa stain}

According to [13] the steps as fix the air-dried film in methanol for 2 minutes. Allow the smear to dry and then immerse it in a solution of 1 part of Giemsa stock solution (commercial liquid stain) to 10 parts of water (PH 7.2) for 45 min. Discard the excess stains and rinses the slides in buffered water. Drain the slides thoroughly in vertical position and allow them to air dry. Wipe the bottom sides of the slide before drying. Mount the stained smears in a neutral mounting medium (Canada balsam or DPX). The slide examination under oil immersion objective (100X magnification), figures (5).

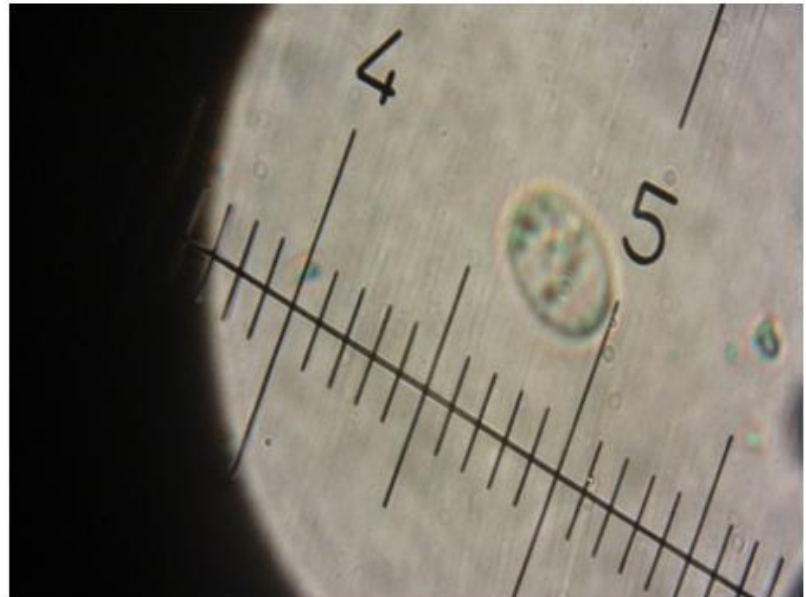

Fig. 2: Photomicrograph of Giardia Cysts: Direct Smear with Norma Saline (400X).

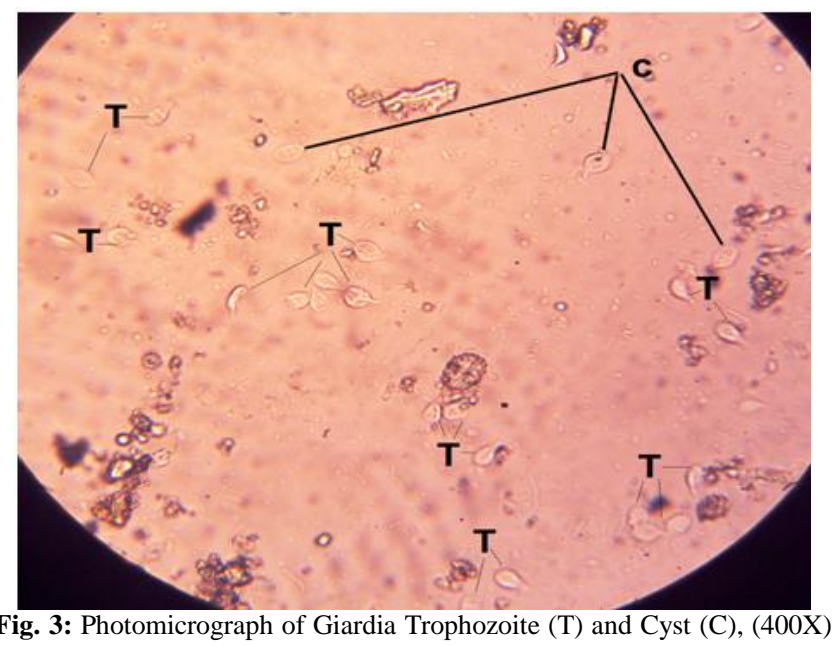

Direct Smear with Normal Saline.

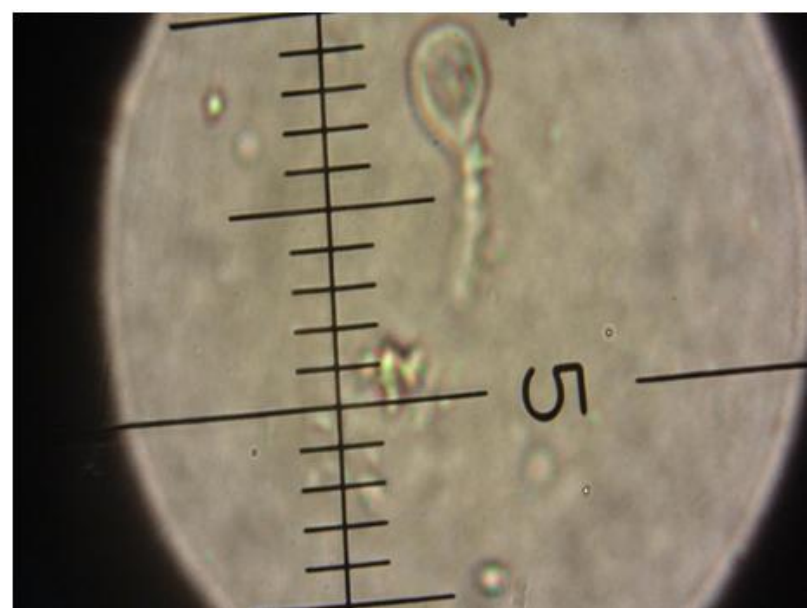

Fig. 4: Photomicrograph of Giardia Trophozoite Direct Smear with Normal Saline (400X). 


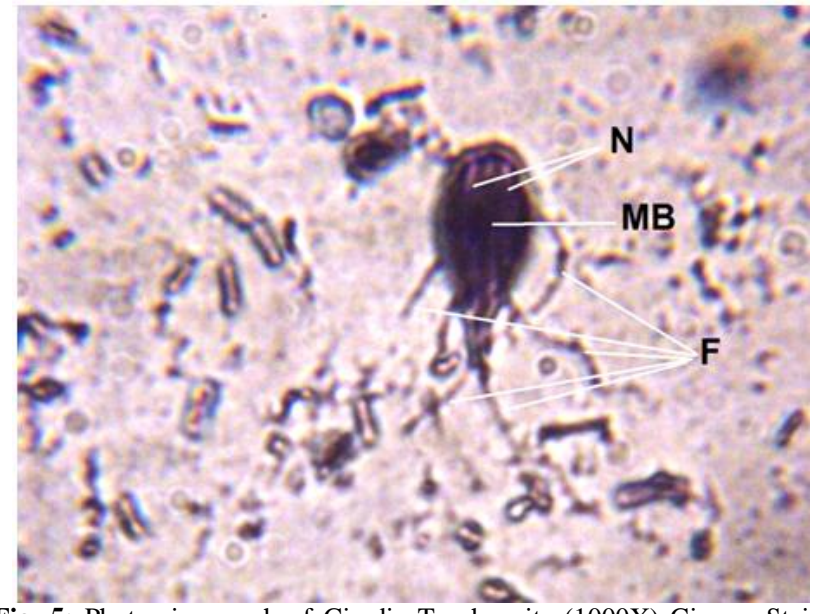

Fig. 5: Photomicrograph of Giardia Trophozoite (1000X) Giemsa Stain (N: Nucli, MB: Median Body, F: Flagella)

\section{Results}

The microscopic examination was done by light microscope at different power (10X, 40X and 100X). Giardia cyst was appear oval in shape, colorless, have 4 nucli, axonemes (axostyle) with and the dimensional measuring were in human $(9-14 \times 6-11 \mu \mathrm{m})$ with average $(11.2 \times 7.3 \mu \mathrm{m})$ and in cow $(8-14 \times 6-10 \mu \mathrm{m})$ with average $(10.6 \times 8.2 \mu \mathrm{m})$, table below. Giardia trophozoites (direct smear and Giemsa staining) were re-sampled pear cut half or teardrop in shape or fun-face shape, binucleate, four pairs of flagella, ventral disc and two median bodies, the diameter were $12-18 \mu \mathrm{m}$ length X 6-8 $\mu \mathrm{m}$ width in cow and 10-18 $\mu \mathrm{m}$ length $\mathrm{X}$ 6-8 $\mu \mathrm{m}$ width in human.

\section{Discussion}

The work results observed under microscopic, Giardia cyst was oval in shape, colorless, have 4 nucli, axonemes (axostyle) with the dimensional measured in human $(9-14 \mu \mathrm{m}$ long $X$ 6-11 $\mu \mathrm{m}$ wide) and the average was $(11.2 \times 7.3 \mu \mathrm{m})$ and in cow $(8-14 \mu \mathrm{m}$ long $\mathrm{X} 6-10 \mu \mathrm{m}$ wide) with the average was $(10.6 \mathrm{X} 8.2 \mu \mathrm{m})$, these results were resampling to results of [3] said: The oval cysts ( 8 to $12 \mu \mathrm{m}$ long by 7 to $10 \mu \mathrm{m}$ wide) ; [15] reported: The cyst measures up to $12 \mu \mathrm{m}$ in length and $8-10 \mu \mathrm{m}$ in width. G. Duodenalis cysts are either round or oval, measure 11-14 $\mu \mathrm{m} \times 7$ $10 \mu \mathrm{m}$ have four nuclei and contain axonemes and median bodies [16]. Cysts are oval-shaped with a thin hyaline wall and dimensions $8-12 / 7-10 \mu \mathrm{m}$, initially, they are bi-nucleated and the mature cyst has four nuclei, curved median bodies and longitudinal axonemes [17]. Giardia trophozoites were resampled pear cut half or tear-drop in shape, binucleate, four pairs of flagella, ventral disc and two median bodies, the diameter were (12-18 $\mu \mathrm{m}$ length X 6-8 $\mu \mathrm{m}$ width in cow and 10-18 $\mu \mathrm{m}$ length $\mathrm{X}$ 6-8 $\mu \mathrm{m}$ width in human) these results were similar with [5] who showed that trophozoites are binucleate, possess four pairs of flagella and an adhesive disc which is located on the ventral surface of the cell. [16] Mentioned that trophozoites are $10-20 \mu \mathrm{m} \times 5-15 \mu \mathrm{m}$, tear drop shaped and exhibit a ventral concave sucking disk, also have four pair of flagella for movement, two axonemes and two organelles called median bodies found near the center. [18] Found the motile trophozoite is pyri-form to pear shape with bilateral symmetry and dimensions $12-15 / 6-8 \mu \mathrm{m}$. The Giardia trophozoite is not similar for all species of Giardia present. [19] Identified morphological differences between trophozoites and proposed that the nomenclature be based on biological difference and not host specificity. Of the 51 species of Giardia that have been described only six can be distinguished on the basis of morphological characters, the remaining species were described principally on the basis of host occurrence [10].
Table 1: Dimensions of Unstained G Lamblia Cysts in Heavily Infection in Cow and Man

\begin{tabular}{|c|c|c|c|c|}
\hline $\begin{array}{l}\text { Specimen num- } \\
\text { ber }\end{array}$ & $\begin{array}{l}\text { Cow } \\
\text { Length } \\
(\mu \mathrm{m})\end{array}$ & $\begin{array}{l}\text { Width } \\
(\mu \mathrm{m})\end{array}$ & $\begin{array}{l}\text { Man } \\
\text { Length } \\
(\mu \mathrm{m})\end{array}$ & $\begin{array}{l}\text { Width } \\
(\mu \mathrm{m})\end{array}$ \\
\hline 1 & 10 & 8 & 10 & 7 \\
\hline 2 & 9 & 6 & 9 & 6 \\
\hline 3 & 9 & 7 & 9 & 6 \\
\hline 4 & 8 & 6 & 12 & 7 \\
\hline 5 & 10 & 8 & 11 & 7 \\
\hline 6 & 12 & 9 & 12 & 7 \\
\hline 7 & 13 & 10 & 11 & 7 \\
\hline 8 & 11 & 9 & 12 & 8 \\
\hline 9 & 11 & 8 & 9 & 6 \\
\hline 10 & 10 & 8 & 12 & 8 \\
\hline 11 & 11 & 9 & 11 & 7 \\
\hline 12 & 11 & 9 & 12 & 7 \\
\hline 13 & 14 & 10 & 11 & 8 \\
\hline 14 & 12 & 9 & 12 & 7 \\
\hline 15 & 12 & 9 & 12 & 8 \\
\hline 16 & 10 & 8 & 13 & 10 \\
\hline 17 & 14 & 10 & 11 & 7 \\
\hline 18 & 9 & 7 & 11 & 7 \\
\hline 19 & 12 & 9 & 9 & 6 \\
\hline 20 & 10 & 8 & 11 & 8 \\
\hline 21 & 8 & 6 & 11 & 6 \\
\hline 22 & 9 & 6 & 12 & 6 \\
\hline 23 & 8 & 6 & 11 & 7 \\
\hline 24 & 12 & 10 & 13 & 9 \\
\hline 25 & 10 & 9 & 11 & 7 \\
\hline 26 & 13 & 10 & 9 & 6 \\
\hline 27 & 12 & 9 & 13 & 9 \\
\hline 28 & 10 & 8 & 11 & 7 \\
\hline 29 & 9 & 7 & 14 & 11 \\
\hline 30 & 10 & 9 & 11 & 7 \\
\hline Average & $10.6(8-14)$ & $8.2(6-10)$ & $11.2(9-4)$ & $7.3(6-11)$ \\
\hline
\end{tabular}

The occurrence of morphological variation within G. Duodenalis has been reported on numerous occasions [20]. This variation has usually involved differences in body dimensions and/or shape. The value of such variation as discriminatory and taxonomic criteria has been extensively reviewed [21], [22]. A part from the characters of size and shape which appear to be of limited value for differentiating species, the major issue has been one of the isolate variability and questionable statistical analyses [22].

\section{Conclusion}

Basrah province is an endemic area for giardiasis. Giardiasis was widely distributed throughout the months of year; however there was no strongly effect of climate factors on the prevalence of giardiasis. Many factors could effected the distribution and prevalence of giardiasis either in human or among cows as socioeconomic status, overcrowding, level of education, sanitation, contact with animals and types of water source. Both Giardia phases showed different measurement in dimensions of both hosts, also through this work concluded different morphology of Giardia stages in both hosts.

\section{Acknowledgement}

We like to thank the Head Manager of Qurnah Health Center Dr. Ahmed S. Al-Shewered, for their helping in this work

\section{References}

[1] Adam RD. 1991, the Biology of Giardia spp., Microbiology Review, 55: 706-732.

[2] Adam RD. 2000, The Giardia lamblia genome, International Journal of Parasitology, 30: 475-484. http://dx.doi.org/10.1016/S0020-7519 (99)00191-5.

[3] Wolfe MS. 1992, Giardiasis, Clinical Microbiology Review, 5: $93-$ 100 . 
[4] Upcroft J. \& Upcroft P. 1998, my favorite cell Giardia, Biology Essays, 20: $256-263$.

[5] Meyer EA. 1994, Giardia as an organism, In: Giardiasis From molecules to Disease, Thompson RCA., Renynoldson JA. and AJ. Lymbery, Holland, Elsevier, Amsterdam, 3-15.

[6] Cheissin EM. 1964, Ultra-structure of G. duodenalis. I. Body surface, sucking disc, and median bodies, Journal of Protozoa, 11: 91-98. http://dx.doi.org/10.1111/j.1550-7408.1964.tb01725.x.

[7] Roberts LS. \& Janovy J. 2009, Foundations of Parasitology, 8th ed, New York, USA, McGraw-Hill Inc.

[8] Friend DS. 1966, the fine structure of Giardia muris, Journal of Cell Biology, 29: 317-332. http://dx.doi.org/10.1083/jcb.29.2.317.

[9] Lujan HD., Marotta A., Mowatt MR., Sciaky N., Lippincott-Schwartz J. \& Nash TE. 1995, Developmental induction of Golgi structure and function in the primitive eukaryote Giardia lamblia, Journal of Biology and Chemistry, 270: 4612-4618. http://dx.doi.org/10.1074/jbc.270.9.4612.

[10]Lujan HD., Mowatt MR. \& Nash TE. 1997, Mechanism of Giardia lamblia differentiation into cyst, Microbiology and Molecular Biology Review, 61: 294-304.

[11]Lujan HD. \& Svard S. 2011, Giardia a Model Organism, 1st ed, Austria. Springer-Verlag/ Wien.

[12]Markell EK., Jone DT. \& Krotoski WA. 1999, Markell and Voges Medical Parasitology, 8th ed, W.B. Saunders co. Philadelphia.

[13]Al-Emarah G., AL-Ali S. \& Al-Idresi S. 2009, Atlas of Parasites, 1st ed, Al-Salam printing, Basrah, Iraq.

[14]Kassab JT. 1979, The relationship of giardiasis in children with the levels of the immunoglobulins ( $\operatorname{IgG}, \operatorname{IgA}, \operatorname{IgM}, \operatorname{IgE}$ ) in serum and intestinal fluids, M. Sc. Thesis, University of Baghdad, Iraq.

[15]Erlandsen SL., Macechko PT., van Keulen H. \& Jarroll EL. 1996, Formation of the Giardia cyst wall: studies on extracellular assembly using immune gold labeling and high resolution field emission, Journal of Eukaryotic Microbiology, 43: 416-429. http://dx.doi.org/10.1111/j.1550-7408.1996.tb05053.x.

[16]Ortega YR. \& Adam RD. 1997, Giardia: overview and update, Clinical Infectious Disease, 25: 545-549. http://dx.doi.org/10.1086/513745.

[17]Ivanov AI. 2010, Giardia and giardiasis, Bulgarian Journal of Veterinary Medicine, 13: 65-80.

[18]ICAIR, Life Systems, Inc. 1984, Criteria Document on Giardia, EPA, and Washington, DC, USA.

[19]Filice FP. 1952, Studies on the cytology and life history of a Giardia from the laboratory rat, Journal of University of California Public Zoology, 57: 53-145.

[20]Monis PT., Andrews RH., Mayhofer G. \& Ey PL. 1998, Novel lineages of Giardia duodenalis identified by genetic analysis of organism isolated from the dog in Australia, Parasitology, 116: 7-19. http://dx.doi.org/10.1017/S0031182097002011.

[21]Thompson RCA., Lymbery AJ. \& Meloni BP. 1990, Genetic variation in Giardia taxonomic and epidemiological significance, Journal of Parasitology, 14: 1-28.

[22]Thompson RCA. \& Monis PT. 2004, Variation in Giardia implications for taxonomy and epidemiology, Advanced Parasitology, 58: 69-137. http://dx.doi.org/10.1016/S0065-308X (04)58002-8. 